\title{
Reasoning under uncertainty within the context of probability education: A case study of preservice mathematics teachers
}

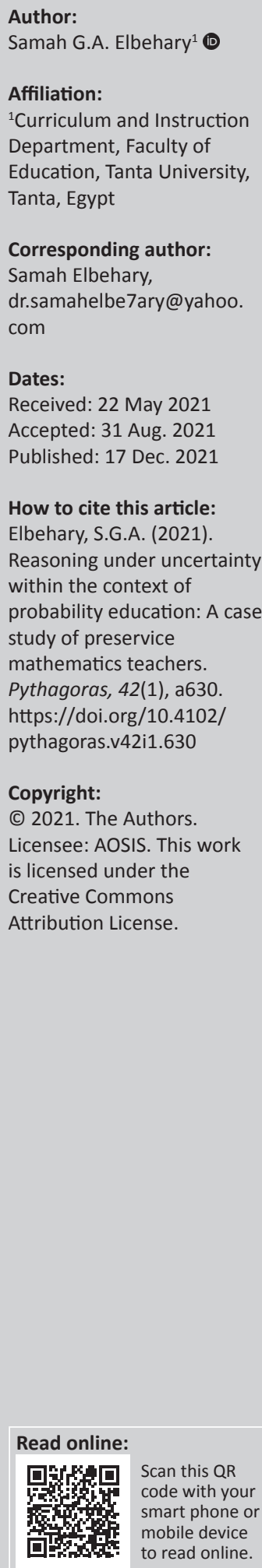

\begin{abstract}
Interpreting phenomena under uncertainty stands as a substantial cognitive activity in our daily life. Furthermore, in probability education research, there is a need for developing a unified model that involves several probabilistic conceptions. From this aspect, a central inquiry has been raised through this study: how do preservice mathematics teachers (PSMTs) reason under uncertainty? A multiple case study design was operated in which a purposive sample of PSMTs was selected to justify their reasoning in two probabilistic contexts while their responses were coded by NVivo, and corresponding categories were developed. As a result, PSMTs' probabilistic reasoning was classified into mathematical (M), subjective (S), and outcome-oriented $(\mathrm{O})$. Besides, several biases emerged along with these modes of reasoning. While $\mathrm{M}$ thinkers shared equiprobability and insensitivity to prior probability, the prediction bias and the belief of Allah's willingness were yielded among $S$ thinkers. Also, the causal conception spread among $\mathrm{O}$ thinkers.
\end{abstract}

Keywords: Allah's willingness; Egypt; preservice mathematics teachers; probability biases; reasoning under uncertainty.

\section{Introduction and research gap}

Interpreting phenomena under uncertainty is a substantial cognitive activity of our daily life, which is encountered constantly in everyday situations. Starting from a simple question, 'is it going to rain tomorrow?', to a more sophisticated inquiry, 'can a person accomplish his future goal?'. Moreover, many professions such as insurance, economics, medicine, physics, and biology require making decisions under uncertainty. As Batanero, Chernoff, Engel, Lee, and Sánchez (2016) declared, to function adequately in society, citizens need to overcome their deterministic reasoning and accept the existence of chance in nature. Hence, this need for probabilistic reasoning has been acknowledged by educational institutions in many countries, and probability has been embedded in the official curricula at various levels, including teacher education.

While the discussion of probabilistic reasoning becomes necessary for all learners at different levels of study, it is particularly crucial for the teacher education of preservice mathematics teachers (PSMTs), those university students who learn to teach intentionally and systematically (Morris, Hiebert, \& Spitzer, 2009). As noted in various studies, one pedagogical difficulty for teaching probability is the mathematics teachers' lack of specific preparation in such content (Ainley \& Monteiro, 2008; Batanero, Burrill, \& Reading, 2011; Batanero, Contreras, Fernandes, \& Ojeda, 2010; Franklin \& Mewborn, 2006; Pecky \& Gould, 2005). Furthermore, fundamental broad statistical knowledge is not adequate for teachers to effectively teach probability (Batanero, Godino, \& Roa, 2004). This situation appears obviously in the Egyptian context, wherein only about $9 \%$ of all subjects during the whole duration of the four-year mathematics teachers' preparation programme has been assigned to study statistics, including probability (Elbehary, 2020). Consequently, because of such limitedness and the specific characteristics of the probability subject that is not usually encountered in other mathematics areas (e.g., multifaceted view and the lack of reversibility), probability education incorporates distinct challenges for both teachers and students (Batanero et al., 2016).

Additionally, and regarding probabilistic reasoning, it has been highlighted by Stohl (2005) that 'the success of any probability curriculum for developing students' probabilistic reasoning depends greatly on teachers' understanding of probability' (p. 351). Such focus on reasoning is compatible with Ball, Lubienski, and Mewborn's (2001) argument concerning the reasoning 
processes, which underpin all teaching practices. As they noted, teachers' knowledge plays a significant role in the quality of their teaching since many activities, such as determining what students know, representing mathematical ideas, and modifying textbooks, involve reasoning and thinking. Moreover, teachers' knowledge itself that consolidates their reasoning manners has been regarded as one factor to determine students' understanding and achievement (Darling-Hammond, 2000; Darling-Hammond \& Sykes, 2003; Fennema \& Franke, 1992; Mosvold \& Fauskanger, 2014; Rivkin, Hanushek, \& Kain, 2005; Schacter $\&$ Thum, 2004). Because of such a relationship between teachers' knowledge and pupils' understanding, the limited emphasis on learning statistics and probability during teacher education may be one factor why the Egyptian pupils' achievement in data and chance remains the lowest among other mathematics areas (Elbehary, 2019).

The aforementioned argument strengthens teachers' probability knowledge that tacitly includes reasoning under uncertainty to positively impact students' learning. 'Teachers' here denotes PSMTs who will teach probability to primary and lower secondary school students. Yet, what is the probability knowledge that students need to acquire? The answer to such a question has been explicitly stated through various professional organisations. For example, the National Council for Teachers of Mathematics (NCTM) recommended Grades 5-8 students explore situations through experimentation and simulation, construct sample spaces to determine the probabilities of various realistic phenomena, and appreciate the practice of probability knowledge in their daily life. Furthermore, middle-grade students should compute probabilities for simple and compound events (NCTM, 1989, 2000). These recommendations are consistent with what the American Statistical Association (ASA) has advocated for studying theoretical probability, experimental probability and simulation processes, and hypothesis testing for college students (Aliaga et al., 2005).

Repeatedly, about the relationship between teachers' knowledge and students' understanding, Papaieronymou (2010) indicated teachers' awareness to confront common probabilistic misconceptions, conduct simulations, and demonstrate probability concepts to students as crucial pedagogical content knowledge that has been highlighted by NCTM, ASA, the American Mathematical Society (AMS), and the Mathematical Association of America (MAA). Acknowledging these recommendations, learning both theoretical and experimental probability is fundamental. This matches the Egyptian curriculum, in which students at primary and lower-secondary grades are expected to acquire theoretical, experimental, and subjective (intuitive) interpretations of probability. On the other side, at the university level, PSMTs should perceive conditional probability and Bayes' theorem.

Chernoff and Sriraman $(2014,2015)$ have classified the probability education research into four periods: (1) the
Piagetian period, which was dominated by Piaget and Inhelder's (1975) investigations of people's probabilistic reasoning. (2) The post-Piagetian period, in which probabilistic reasoning was reviewed through Fischbein's (1975) research, focusing on primary and secondary intuitions, and Tversky and Kahneman's (1974) investigations regarding judgmental heuristics of adults when they reason under uncertainty, in the field of psychology. (3) The contemporary research period, which witnessed a significant shift towards examining curriculum, instruction, probabilistic intuitions, and learning difficulties; it was led by a group of researchers in the mathematics education field (e.g., Falk, 1986; Konold, 1989, 1991). (4) The assimilation period started after 2000 while the research continues to develop models, frameworks, and theories associated with intuition and learning difficulties in probability, in line with the previous period. At this stage, the probability education research has been shifted smoothly from replicating and importing research findings of other fields (e.g., psychology) to develop its specific interpretations of results stemming from difficulties associated with teaching and learning probability, under the umbrella of mathematics education. Nevertheless, recent investigations shed light on a renaissance period of psychological research in mathematics education (e.g., Chernoff, 2012; Chernoff \& Russell, 2012; Chernoff \& Sriraman, 2015).

Based on this historical development of probability education research, some areas for future study have been identified; one of these concerns is developing a unified framework that models several conceptions of probability (Chernoff \& Russell, 2014; Jones, Langrall, \& Mooney, 2007; Shaughnessy, 1992). This trend of research has been recommended for further clarification, particularly regarding the witnessed contested area about the nature of probability, as the theory of probability itself has a mathematical side and a foundational or a philosophical side (Chernoff \& Sriraman, 2015). From this aspect, a central inquiry has been raised through the current study: how do PSMTs reason under uncertainty? In other words, what are the characteristics of PSMTs' probabilistic reasoning, which implies a cognitive activity associated with a context containing uncertainty elements (Savard, 2014)? Exploring PSMTs' probabilistic reasoning may contribute to the existing literature by modelling their probability conceptions in one schema.

\section{Theoretical perspective}

Many previous studies showed that adults (including university students) have various conceptions about probability and relevant biases in reasoning under uncertainty (e.g., Batanero \& Sanchez, 2005; Dollard, 2011; Fischbein \& Schnarch, 1997; Kazak \& Pratt, 2017; Konold, 1989; Konold, Pollatsek, Well, Lohmeier, \& Lipson, 1993; Tversky \& Kahneman, 1974). Moreover, and as noted by Stohl (2005), without specific training in probability, preservice and practising teachers may employ their intuitions and beliefs. Despite that, there is no further discussion that represents PSMTs' probabilistic conceptions in a unified schema. 
To address this, the current study has acknowledged that 'learners' conceptions are underlined by their way of reasoning towards a certain phenomenon' to be the essential hypothesis. Alternatively, one way to identify PSMTs' probabilistic conceptions is to explore how they reason under uncertainty.

Conception defines a mental filter to interpret a situation and make sense of it (Giordan \& Pellaud, 2004); it helps to keep a balanced cognitive structure when learners adapt a new knowledge (Piaget, 1975). Conceptions can be valid in some contexts, but they cannot be generalised across all. For this reason, they preferably should not be described as misconceptions because they still work in certain circumstances (Giordan, 1998). Therefore, Savard (2014) argued that, concerning probability knowledge, it is not reasonable to pretend that a certain conception could accurately explain a certain level of conceptual understanding. This is because classifying conceptions in a normative way does not declare the value of learners' reasoning to understand the world.

Furthermore, and on the relationship between learners' conceptions and their probabilistic reasoning, while probabilistic conceptions are rooted in different epistemologies, these epistemologies themselves are emphasised by the reasoning employed to think of a phenomenon. In this regard, Konold (1989) distinguished the formal knowledge of probability and natural judgmental heuristics as two types of cognition when reasoning under uncertainty. Later, Savard (2014) redefined cognition under uncertainty as probabilistic reasoning versus deterministic reasoning, which has inspired the current study.

In light of Savard's (2014) clarification, probabilistic reasoning considers two significant factors: variability and randomness. On one hand, variability indicates that the outcome is not fixed; it alters depending upon the probable favourable cases (i.e., theoretical probability), the frequencies (i.e., experimental probability), or some evaluation criteria (i.e., subjective probability) (Canada, 2006; Garfield \& Ben-Zvi, 2005). On the other hand, randomness implies uncertainty and independence; while the former reflects that the event cannot be predicted with certainty, the latter indicates no correspondence between what happened before and the new outcome (Dessart, 1995; Green, 1993). In contrast, deterministic reasoning seeks correlation, using present and past information to describe an event. There is dependence between the events that might justify a result. Besides, the deterministic estimation indicates an accurate prediction (Briand, 2005), in which there is no uncertainty.

From an educational viewpoint, probabilistic reasoning signifies a principal reason why probability is involved in the school curriculum, as the study of probability sustains the creation of probabilistic reasoning. It supports learners, formally, to structure their vague thinking about random phenomena (Borovcnik \& Peard, 1996). Additionally, because of the increasing number of events described in terms of risk, understanding the related concepts to reason under uncertainty should be investigated (Martignon, 2014; Pange \& Talbot, 2003). That is consistent with the need to overcome the individuals' deterministic thinking and admit the presence of chance in nature (Batanero et al., 2016).

The above argument reflects the process of probabilistic reasoning as an expected capability that students should acquire through learning the content of probability, either at pre-university or at teacher education level. This appears clearly in forthcoming research of probability that flows from discussing informal reasoning toward clarifying fallacious reasoning (Chernoff, 2012). Following this trend, there is a demand for further studies that focus on fallacious reasoning, especially since many of these fallacies still account for both correct and incorrect responses. This direction emphasises the individual justification and reasoning processes rather than their typical normative answers. It also meets the renaissance period of psychological research in mathematics education, in which there is a need to investigate 'theories about mathematics education and cognitive psychology to recognize and incorporate achievements from the other domain of research' (Gillard, Dooren, Schaeken, \& Verschaffel, 2009, p. 13).

Additionally, and about the current literature, few studies were reported on PSMTs' knowledge and reasoning (e.g., Batanero et al., 2010; Dollard, 2011; Estrella \& Olfos, 2010; Ives, 2007; Torres, 2014), and it recommended much more research to clarify the essential components in PSMTs' preparation. For a case, within the recent contributed papers of the International Conference on Teaching Statistics (ICOTS 8 [2010], 9 [2014], and 10 [2018]), which is considered a platform to exchange ideas and experiences among statistics educators under the authorisation of the International Association for Statistic Education (IASE), only three papers were found. Savard's (2010) study aimed at interpreting primary school students' probabilistic thinking in some artificial gambling situations, and it reported that those students practised deterministic reasoning to predict the outcome. Besides, understanding variability was highlighted as an essential concept in thinking probabilistically. Moreno and Cardeñoso's (2014) study revealed four hieratical levels of probabilistic thinking (i.e., deterministic, personalistic, uncertain, and contingency), and it confirmed a certain distance between teachers' mental models and the standard conceptual models in probability theory.

While those two papers addressed the characteristics of learners' probabilistic thinking, the third article was provided by Primi, Morsanyi, and Chiesi (2014) to develop a scale for measuring the basics of probabilistic reasoning ability.

These studies stressed the approach of classification and assessment with less reflection on the nature of the reasoning process itself, except Savard's (2010) paper which provided a motive for the current study wherein it is not possible to pretend that a certain conception explains a level of understanding, as remarked earlier. Accordingly, to 
contribute to the forthcoming literature, this study intended to model PSMTs' reasoning under uncertainty and related conceptions, not as a hierarchical order of conceptual understanding (e.g., normative or optimal solution), but rather through emphasising the way of reasoning per se. From this aspect the current study admits two things: (1) teaching probability rarely builds upon authentic contexts and predominantly uses a theoretical approach, in which most encountered tasks in both $\mathrm{K}-12$ and teacher education curricula incorporate a well-defined quantifiable sample space (e.g., tossing a coin, rolling dice); (2) the deficiency of such traditional tasks to afford an adequate foundation for learning subjective probability (Azcárate, Cardeñoso, \& Serradó, 2006; Stohl, 2005). Given these considerations, the current study has adapted an authentic probabilistic situation (in addition to a pedagogical activity) to explore PSMTs' probabilistic reasoning (see the method section).

Further to this, and from a psychological viewpoint, the world of personal intuition signifies one source of success or failure in teaching since these intuitions determine whether learners accept or ignore what they learn. Accordingly, Kapadia and Borovcnik (2010) remarked that to think probabilistically, it is time to replace Heitele's (1975) ideas with an approach that studies concepts more from a nonmathematical perspective. Because of that, assessing the application of probability models to real phenomena was regarded as a crucial skill for interpreting random events (Martignon, 2014), particularly in teacher education wherein the activities proposed for PSMTs during their preparation are generally stereotyped.

It brings the concept of probability to the notion of calculating the relative frequency of occurrences of an event (Musch \& Ehrenberg, 2002). Accordingly, because teaching probability seldom depends on exploring authentic situations, employing a realistic context can cultivate analysing PSMTs' probabilistic reasoning. It defines a mode of thinking associated with judgments under uncertainty and is related to real-life phenomena (Falk \& Konold, 1992).

\section{Method \\ Research design}

Since the central goal of this study is modelling PSMTs' probabilistic reasoning and related conceptions, the case study design as a form of qualitative research was employed to answer its inquiry. Accordingly, the investigator can explore a bounded system (PSMTs at the Faculty of Education, Tanta University, Egypt) through in-depth data collection for reporting a case description and case-based themes (Creswell, 2009). More precisely, the current study has utilised the multiple case study design; it considers the logic of replication, in which the inquirer replicates the procedures for each case (Yin, 2003). Although qualitative researchers are reluctant to generalise from one case to another because the context of cases differs, triangulating the gathered data is still necessary; it minimises bias and personal effects on the research findings (Ticehurst \& Veal, 2000).
Therefore, using the multiple case study design increases the validity of the intended model, which, in this study, represents PSMTs' probabilistic reasoning. As regarded by Weyers, Strydom, and Huisamen (2008), during the data triangulation process, strong similarities could be viewed as a validation of data or conclusions.

\section{Participants}

Based on the case study research processes (Creswell, 2009), the following procedures were conducted:

First, a purposive sample of PSMTs who study the mathematics education course at the Faculty of Education, Tanta University, Egypt, during the academic year $2018 / 2019$ was selected in light of two criteria. While the first criterion signified the participants' convenience about time and willingness to be engaged (Lopez \& Whitehead, 2013), prior knowledge regarding the three principal interpretations of probability (i.e., theoretical, experimental, and conditional) represented the second standard. The reason for such a criterion is clarifying PSMTs' biases and conceptions that persist even under formal education. Accordingly, 68 PSMTs were selected to participate in the current study, as they studied the three interpretations of probability in both pre-university and teacher education. In the Egyptian context, learners learn theoretical and experimental probability during the primary and middle grades, while conditional probability is introduced in higher secondary school. Moreover, these concepts have to be studied further as a part of a four-year preparation programme for mathematics teachers (Elbehary, 2019). Table 1 shows characteristics of the study sample (taken into consideration that first-year students could not participate in this study because they almost have a full schedule).

\section{Data collection and analysis processes}

Secondly, two probabilistic situations (i.e., giving birth and throwing a die) were offered through a questionnaire prepared by the researcher, which should be performed within 30 minutes. This matches what Hancock and Algozzine (2006) noted, wherein the examined documents by a case study researcher include instruments in the form of

TABLE 1: The study population and sample.

\begin{tabular}{lccccc}
\hline Variable & \multicolumn{3}{c}{$\begin{array}{c}\text { Number of preservice mathematics teachers who } \\
\text { were enrolled for the academic year 2018/2019 }\end{array}$} & \multirow{2}{*}{ Total } \\
\cline { 2 - 4 } & 1st year & 2nd year & 3rd year & 4th year & \\
\cline { 1 - 3 } $\begin{array}{l}\text { Total } \\
\text { population }\end{array}$ & 107 & 99 & 92 & 102 & 400 \\
$\begin{array}{l}\text { Study sample } \\
\text { (participants) }\end{array}$ & $\begin{array}{c}\text { Not } \\
\text { available }\end{array}$ & 32 & 23 & 13 & 68 \\
$\begin{array}{l}\text { Basic studied } \\
\text { concepts of } \\
\text { probability }\end{array}$ & $\begin{array}{c}\text { Not } \\
\text { available }\end{array}$ & $\begin{array}{l}\text { 1. Basic concepts: Random experiment, sample space, } \\
\text { event, mutually exclusive and exhaustive events, } \\
\text { probability of an event, equally likely principle, } \\
\text { probability function, probability axioms, conditional } \\
\text { probability, independent events, and Bayes theorem. } \\
\text { 2. Random variables (e.g. discrete and continuous } \\
\text { random variable, density function, mathematical } \\
\text { expectation). } \\
\text { 3. Probability distributions (e.g. Bernoulli, Binomial, } \\
\text { Poisson, Gamma, Exponential, Beta, Normal). }\end{array}$ \\
\hline
\end{tabular}


TABLE 2: The probability contexts within the Egyptian school curriculum.

\begin{tabular}{|c|c|c|c|c|c|}
\hline \multirow[t]{2}{*}{ Identified context } & \multirow[t]{2}{*}{ Example } & \multicolumn{2}{|c|}{ Number of activities ${ }^{1}$} & \multicolumn{2}{|c|}{ Total } \\
\hline & & Primary level & Lower secondary level & $n$ & $\%$ \\
\hline Environmental issues & Rain, sun, day and night, weather forecast & 5 & 0 & 5 & 4.7 \\
\hline School experiences & Grades, success, results of a competition & 5 & 4 & 9 & 8.5 \\
\hline Gender & Boys and girls, giving birth & 4 & 1 & 5 & 4.7 \\
\hline Life expectancy & Life expectancy and insurance concerns & 1 & 2 & 3 & 2.8 \\
\hline Preferences & Family visits, preferred food, language, sport, newspaper, transportation & 4 & 5 & 9 & 8.5 \\
\hline Quasi-pedagogical & $\begin{array}{l}\text { Draw a ball, toss a coin, drop a pin, roll a die, span a spinner, draw a card of } \\
\text { two-digit numbers, drop a stick }\end{array}$ & 40 & 26 & 66 & 62.3 \\
\hline Total number & & 60 & 46 & & \\
\hline
\end{tabular}

surveys or questionnaires that often provide powerful means to collect data regarding the study questions. Yet, before listing the questionnaire items, the following section describes the process of selecting the appropriate contexts within which PSMTs' probabilistic reasoning can be modelled.

Acknowledging that PSMTs in this study are being prepared to teach primary and lower secondary pupils, the implemented activities of probability, provided by the national textbooks for these grades, were characterised inductively based on the context. In other words, the researcher tried to consolidate the probability tasks of similar circumstances together. Consequently, seven different settings were inferred (see Table 2).

From Table 2, it is apparent that the school curriculum emphasises traditional mathematical activities. Hence, the activity of throwing a die was included in the study questionnaire. Nonetheless, because these activities cannot provide an adequate foundation for defining subjective probability, as noted earlier, another context was utilised. For this, and in light of previously inferred probability contexts, a survey was prepared (see the Appendix) and administered to the study participants. They were asked to determine the appropriateness of each context to address each probability interpretation (i.e., theoretical, experimental, and conditional), knowing that some contexts can be adapted to approach more than one concept. As a result, PSMTs judged that all settings could be employed to address multiple probability interpretations. Nevertheless, the contexts of life expectancy, gender, and school experiences signified (1) probabilistic circumstances where the subjective interpretation strongly exists (i.e., around 25\%, 22\%, and 27\%), and (2) balanced choices across the probability interpretations (see Figure 1).

Admitting that (1) a clear sample space, (2) easily identified chance factors, and (3) strong cultural prescription towards viewing the phenomena statistically are the criteria for judging the difficulty of the reasoning process (Nisbett, Krantz, Jepson, \& Kunda, 1983), randomising devices (e.g., the activity of throwing a die) are easy to reason. Nonetheless, in the social domain (e.g., gender), the sample space is often obscure, and repeatability is hard to imagine; thus, life

1.Note that the total number of the reviewed probability tasks equals 106. This is al the activities that have been raised within the lesson content of both primary and lower-secondary grades, from Grade 3 , when probability is first introduced, until Grade 9.

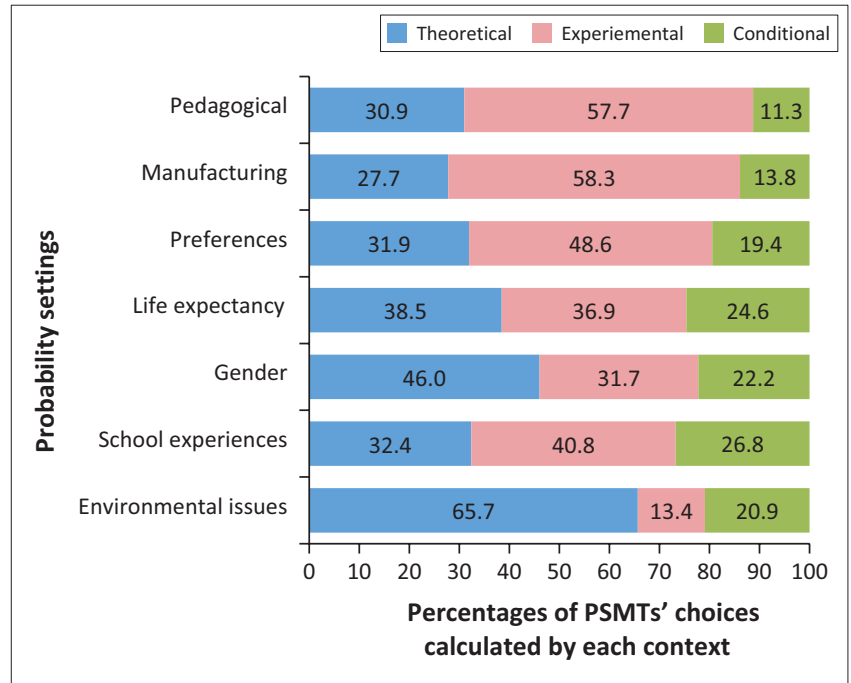

PSMT, preservice mathematics teachers.

FIGURE 1: Preservice mathematics teachers' determination of the probability context.

expectancy and gender were judged as difficult contexts to reason. Still, the gender context appears within the curriculum more than the life expectancy context (see Table 1). As a result, the activity of giving birth was preferred to be considered in the questionnaire. Therefore, to address PSMTs' reasoning under uncertainty, they were asked to answer the following items:

- Item A: Knowing that there is a pregnant woman

- How can you determine the probability of giving birth to a girl?

- Are there any conditions for why you have chosen the proposed ratio of probability?

- Item B: How will you explain to your prospective learners the various strategies that one can employ to determine the probability of getting 5 in a random experiment of rolling a die one time?

Lastly, after the participants responded to the proposed questionnaire, their interpretations were collected and coded by NVivo software. In detail, the coding procedures were conducted as explained below

At first, the obtained data from the study questionnaire were textual, with some mathematical explanations in most cases. For example, about the first item, some PSMTs noted that: 'The probability of giving birth to a girl $=P(G)=1 / 2$, since 
the sample space $(S)=\{$ boy, girl $\}$, and the number of favourable outcomes $=n(G)=1^{\prime}$. Similarly, for the second item, they responded: 'The probability of getting five $=\mathrm{P}(5)=1 / 6$, because $\mathrm{S}=\{1,2,3,4,5,6\}$ and $\mathrm{n}(5)=1^{\prime}$. Furthermore, two rounds of coding processes were employed: (1) An inductive cycle started by investigating PSMTs' responses to the first item. This is argued by Linneberg and Korsgaard (2019) as there is a strong tradition in qualitative research concerning developing codes directly from data rather than using theoretical or prior understandings of the researcher. (2) A deductive cycle was used to develop the inductive probabilistic reasoning categories that worked during this cycle as a lens for examining the answers to the second item (Miles, Huberman, \& Saldana, 2013). Such procedures were handled case by case, starting with analysis of the responses of second-year PSMTs, extending to third-year PSMTs, and ending with fourth-year PSMTs, as recommended in multiple case study design. During the first cycle of coding, which is inductive, using NVivo, the following steps were followed (Thomas, 2006):

- Determine a label for each node that is a short phrase to refer to it. For example, there are no specific conditions to determine the probability, or there are some conditions like the number of sample space elements, knowing the biological or genetic state, admitting miscarriage as a possible result, knowing the previous babies' gender, or it is a matter of Allah's will.

- Describe the scope of each node. For example, the node of no conditions identified PSMTs who agreed that there are no restrictions to determine the probability, it is just a matter of mathematical calculation of the number of favourable cases (one case: girl) divided by the number of all outcomes (two: boy and girl). Additionally, if PSMTs acknowledged some criteria to limit the probability, these criteria were categorised based on their nature (source) and focus point (i.e., determine the likelihood or approve the outcome). For a case, the assigned responses to 'it depends on the number of sample space elements' node have a numerical nature and probability emphasis. Nevertheless, if the criterion was not mathematical (e.g., using baby sonar, observing the woman's physical appearance), the response was committed to another distinct node.

- Illustrate some examples of texts associated with nodes. For instance, the typical response for PSMTs who were assigned to the node 'it depends on $n(S)$ ' was: 'if $S$ has two elements, then $P(G)=50 \%$; similarly, if $S$ has three outcomes, $\mathrm{P}(\mathrm{G})=33.3 \%$. Moreover, for the nonmathematical justifications, although PSMTs provided some percentages to determine the probability of giving birth to a girl, they emphasised several criteria that may alter these percentages. As for the node of the 'using baby sonar', PSMTs reported 50\% to describe the probability; however, they declared that knowing the results of baby sonar could change this probability.

- Create links among several nodes. During this stage, all emerged codes were restructured into two broad categories of (1) probability-focused and (2) outcome- oriented. The probability-focused group was further branched into (1) mathematically oriented that indicates the PSMTs who emphasised the mathematical rules (e.g., $50 \%$ because of calculation procedures), and (2) subjectively oriented that denotes who displayed individual non-mathematical criteria; still, their focus is how to estimate the probability based on these criteria.

- Incorporate the emerged categories into a model. Following the emergence of the three groups, the principal interpretations of probability (i.e., theoretical, experimental, and conditional) were utilised as a framework in which these categories can be consolidated and theorised; that helps to model PSMTs' probabilistic reasoning (see the results section).

This detailed description helps ensure transparency in such a qualitative study; it reflects how the study findings are linked to the collected data (Elo et al., 2014). Furthermore, the second coding cycle, which was operated deductively, had intended to explore how PSMTs responses persisted in a different context by which study results could be further verified. Thus, through implementing the backward direction, PSMTs' responses to the second item (i.e., throwing a die) were analysed in light of the emerged categories from the first coding cycle. Nevertheless, in a few cases, there were some discrepancies between PSMTs' responses to both items. Such cases were highlighted and are discussed within the results section.

\section{Results and discussion}

To respond to the study question (i.e., How do PSMTs reason under uncertainty?), PSMTs were motivated to state their conditions and relevant criteria in which their estimation can be changed. Therefore, to capture the characteristics of their probabilistic reasoning, the giving birth activity was first discussed with them in this manner: Suppose a pregnant woman asks you to help her estimate the probability of giving birth to a girl? What do you think of such a situation? Do you have any criteria or standards to make a judgment concerning the probability? However, the task of throwing a die didn't need more clarification since PSMTs used to practise this. Accordingly, the participants employed different ways of reasoning that are categorised as follows:

- Mathematically oriented thinkers (see Table 3)

- Subjectively oriented thinkers (see Table 4)

- Outcome-oriented thinkers (see Table 5).

\section{Characteristics of mathematically oriented thinkers $[M=m$ and $m$ * reasoning]}

The reasoning for both type $\mathbf{m}$ and $\mathbf{m *}$ (M thinkers) has a common feature of relying on theoretical probability. PSMTs modelled the given situation through the notion of $S$ and the favourable outcome $\mathrm{G}$ for the giving birth activity. Similarly, 49 PSMTs shaped the experiment of throwing a die using a sample $S$ that contains six different possibilities with the favourable outcome being 5 . 
TABLE 3: Mathematically oriented thinkers ( $m$ and $m$ * reasoning) ${ }^{2}$.

\begin{tabular}{|c|c|c|c|c|}
\hline \multirow[t]{3}{*}{ Variable } & \multicolumn{4}{|c|}{ Type $M$ thinkers ( $m$ and $m *$ ) } \\
\hline & \multicolumn{2}{|r|}{ The problem of giving birth } & \multicolumn{2}{|c|}{ The task of throwing a die } \\
\hline & m & $\mathrm{m}^{*}$ & m & $\mathrm{m}^{*}$ \\
\hline Typical response & $\begin{array}{l}\text { P equals } 50 \% \text {, without certain } \\
\text { conditions, because } S \text { contain two } \\
\text { events that are } B \text { and } G \text {. Then, } \\
\text { mathematically, } S=\{B, G\}, P(G)= \\
n(G) / n(S)=1 / 2=50 \%\end{array}$ & $\begin{array}{l}\text { It depends on the number of events in } S \text {. For example, if } \\
S=\{B, G\} \text {, then } P(G)=50 \% \text {. On the other hand, if } S=\{B, G \text {, } \\
\text { twins }\} \text {, then } P(G)=33.3 \% \text {. Hence, based on the stated } \\
\text { hypotheses, particularly the number of elements in } S \text {, the } \\
\text { expected probability will be varied (increased or decreased) }\end{array}$ & $\begin{array}{l}S=\{\text { side } 1 \text {, side } 2 \text {, side } 3 \text {, side } 4, \\
\text { side } 5, \text { side } 6\} \text {, and } A=\text { side } 5 \text {, } \\
\text { Then } P(A)=n(A) / n(S)=1 / 6\end{array}$ & $\begin{array}{l}S=\{1,2,3,4,5,6\} \text { and } \\
A=\{5\} . \text { Then, } P(A)=n \\
(A) / n(S)=1 / 6\end{array}$ \\
\hline (2nd, 3rd, 4th) & $(10,4,1)=15$ & $(4,0,1)=5$ & $(11,0,2)=13$ & $(21,11,4)=36$ \\
\hline
\end{tabular}

TABLE 4: Subjectively oriented thinkers $\left(S=s, s^{*}\right.$, and $s * *$ reasoning)

\begin{tabular}{|c|c|c|c|c|c|}
\hline \multirow[t]{3}{*}{ Variable } & \multicolumn{4}{|r|}{ The problem of giving birth } & \multirow{3}{*}{$\begin{array}{l}\text { The task of } \\
\text { throwing a die }\end{array}$} \\
\hline & \multicolumn{4}{|c|}{ The probability of giving birth to a girl changes depending upon } & \\
\hline & \multicolumn{4}{|r|}{ Type $S$ thinkers $\left(s, s^{*}\right.$, and $\left.s^{* *}\right)$} & \\
\hline Typical response & $\begin{array}{l}\text { our information } \\
\text { about baby sonar } \\
\text { results } \\
\text { (ultrasound scan) }\end{array}$ & $\begin{array}{l}\text { having information } \\
\text { about the woman's } \\
\text { previous babies' } \\
\text { gender }\end{array}$ & $\begin{array}{l}\text { s* } \\
\text { 'Illah's will } \\
\text { 'Insha'Allah' }\end{array}$ & $\begin{array}{l}\begin{array}{l}\text { our information regarding the possible outcomes, understanding the biological or } \\
\text { for example considering miscarriage or }\end{array} \\
\text { spontaneous abortion as a possible outcome, or } \\
\text { (e.g. the issues of } X \text { and } Y \\
\text { knowing that the woman may give birth to twins chromosomes) } \\
\text { changes the probability from } 1 / 2 \text { to } 1 / 3\end{array}$ & Null \\
\hline \multirow[t]{2}{*}{ (2nd, 3rd, 4th) } & $(1,3,2)=6$ & $(1,0,0)=1$ & $(0,1,1)=2$ & $(10,13,5)=32$ & $(0,0,0)=0$ \\
\hline & $(2,3,2)=7$ & & & $(12,14,6)=32$ & \\
\hline Total & 7 cases & & 2 cases & 32 cases & No cases \\
\hline
\end{tabular}

TABLE 5: Outcome-oriented thinkers (o, o*, and o** reasoning).

\begin{tabular}{|c|c|c|c|c|c|}
\hline \multirow[t]{4}{*}{ Variable } & \multicolumn{5}{|c|}{ Type 0 thinkers $\left(0,0^{*}\right.$, and $\left.0^{* *}\right)$} \\
\hline & \multirow{2}{*}{\multicolumn{3}{|c|}{$\begin{array}{l}\text { The problem of giving birth } \\
\text { We can know that the woman will give birth to a girl through }\end{array}$}} & \multicolumn{2}{|c|}{ The task of throwing a die } \\
\hline & & & & \multirow{2}{*}{$\begin{array}{l}\text { We can get the number } 5 \text { if } \\
0^{*}\end{array}$} & \multirow{2}{*}{$\begin{array}{l}\text { The probability to get the number } 5 \\
0^{* *}\end{array}$} \\
\hline & 0 & o* & & & \\
\hline Typical response & $\begin{array}{l}\text { checking the outcome of the } \\
\text { delivery process. Accordingly, if the } \\
\text { woman already gave birth to a boy } \\
\text { or twins, or she had a miscarriage, } \\
\text { or passed away during the delivery } \\
\text { process, the probability will change } \\
\text { from } 1 / 2 \text { to } 0\end{array}$ & $\begin{array}{l}\text { observing the } \\
\text { woman's bodily } \\
\text { appearance } \\
\text { (e.g. belly shape) }\end{array}$ & $\begin{array}{l}\text { recognising whether this } \\
\text { woman gives birth to a } \\
\text { certain gender always, } \\
\text { or not; if yes, and she } \\
\text { usually gives birth to } \\
\text { girls, the probability will } \\
\text { be higher than } 50 \%\end{array}$ & $\begin{array}{l}\text { the die was controlled, an } \\
\text { expert person experimented, } \\
\text { or the number of trials has } \\
\text { been increased }\end{array}$ & $\begin{array}{l}\text { depends on the ratio between the } \\
\text { number of } 5 \text { repetitions and the } \\
\text { total number of many identical } \\
\text { trials; and, if the experiments were } \\
\text { increased, the frequentist } \\
\text { probability meets the theoretical }\end{array}$ \\
\hline \multirow[t]{2}{*}{ (2nd, 3rd, 4th) } & $(2,1,0)=3$ & $(0,0,2)=2$ & $(2,0,0)=2$ & $(0,6,2)=8$ & $(0,6,5)$ \\
\hline & 3 cases & $(2,0,2)=4$ cases & & 8 cases & 11 cases \\
\hline Total & 7 cases & & & 19 cases & \\
\hline
\end{tabular}

In this regard, $\mathbf{M}$ thinkers (both $\mathbf{m}$ and $\mathbf{m}^{*}$ ) understood the idea of variability, wherein the result is not determined, but varies depending on the possible favourable cases (i.e., elements of S) (Garfield \& Ben-Zvi, 2005). M thinkers also maintained the equiprobable bias (Lecoutre \& Fischbein, 1998; Savard, 2014), since they judged the possibility of giving birth to a girl to be equal to a boy; furthermore, when they considered twins as a possible outcome, they supposed that the probability of giving birth to twins is as same as boy or girl.

Holding the equiprobable bias hindered $\mathbf{M}$ thinkers from reflecting on the base rate frequencies (i.e., the actual gender distribution). Accordingly, their responses to the problem of giving birth indicated the insensitivity to the prior probability of outcomes bias (Tversky \& Kahneman, 1974). The respondents ignored that the possibility of giving birth to a girl is slightly less than a boy as the actual gender distribution in Egypt shows the ratio between boys to girls equals 1.06 at birth (NationMaster, 2021). Certainly, PSMTs are neither required nor expected to give a specific correct percentage for the

2. Note that: $\mathrm{P}=$ probability, $\mathrm{S}=$ sample space, $\mathrm{G}=$ girl, $\mathrm{B}=\mathrm{boy}$, and $\mathrm{A}=$ the favourable outcome. gender distribution throughout the country, but should preferably indicate the base rate frequency as a necessary factor to consider when judging under uncertainty. Hence, the notion of the population should be regarded to estimate a reasonable value.

For the second activity, $\mathbf{M}$ thinkers did not confirm the condition of equiprobability, which is required to utilise Laplace theory. While the complexity of physical circumstances (e.g., air resistance, speed) illustrates why individuals cannot predict whether or not a particular outcome will occur when rolling a die (Stohl, 2005), the theoretical probability considers one approach that embodies such complexities. Accordingly, although PSMTs may think of this condition as just a premise for all chance games, there was no explicit information concerning the die regularity.

Such a result resembles Chiesi and Primi's (2009) findings that indicate the prevalence of equiprobability and insensitivity to the prior probability biases among college students.

Chiesi and Primi's (2009) study participants exposed the equiprobability regardless of the actual proportion 
(i.e., ratio of green and blue balls). This mirrors $\mathbf{M}$ thinkers wherein the equiprobable bias hindered them ensuring the prior probability of giving birth to a girl based on the whole population; likewise, speculating the die regularity before determining the chance of obtaining 5. Yet, $\mathbf{M}$ thinkers diverged between type $\mathbf{m}$ and $\mathbf{m} *$, in that there is a slight difference between them in terms of the essence of equiprobable bias.

On one hand, type $\mathrm{m}$ respondents thought that random events are naturally equiprobable, even when they are not (Lecoutre,1992). This is perhaps related to the representativeness heuristic: it denotes judging the likelihood of an event according to how well such event represents some aspects of the parent population or how it matches the system that generated it, which is the case of $\mathbf{m}$ thinkers (Kustos \& Zelkowski, 2013; Pratt \& Kazak, 2018). They focused on the random process, which appeared clearly in their description: 'both situations imply random experiments, and [the] outcomes have the same chance to occur, regardless of any conditions'.

In detail, for the activity of throwing a die, 13 cases were assigned to the $\mathbf{m}$ thinkers category. They strengthened the physical structure of the die itself, so the numbers here symbolise its various facets, and the favourable outcome of 5 means one side among six sides. Although the respondents understood the meaning of numbers as a symbolisation of the die facets, they did not confirm die regularity, as noted first. One possible reason for that is the representativeness heuristic, which prevented PSMTs from confirming the theoretical probability assumptions (Laplace theory axioms) and shaped their perception of randomness. Such a link between students' understanding of randomness and their perspectives on probability was highlighted by Ives (2007). That is, $\mathbf{m}$ thinkers who modelled the situations through theoretical probability believed that randomness is bounded to equiprobability. As reported by Batanero, Green, and Serrano (1998):

in the classical conception of probability we would say that an object (or an event) is a random member of a given class if there is the same probability for [it as there is for] any other member of its class. (p. 115)

On the other hand, type $\mathbf{m}^{*}$ responses reflect a more abstract mindset; they attempted to overgeneralise applying the theoretical probability to all situations, whether these situations are realistic (e.g., giving birth) or technical (e.g., simulators). Consequently, the equiprobable bias in type $\mathbf{m}$ * was inherited in the overgeneralization heuristic: it directed their thinking towards interpreting the giving birth problem like tossing a coin or drawing a card. Accordingly, although $\mathbf{m}$ * thinkers admitted the limitations of $S$ to restrict the probability of giving birth to a girl, they were reluctant to connect these mathematically stated limitations with the actual circumstances that may occur in reality.

Such manner of reasoning was also scrutinised in the second activity, in which 36 PSMTs created S with six possible outcomes (1, 2, 3, 4, 5, and 6) and accordingly determined $P$ (5) $=1 / 6$ (see Table 3 ). They sharpened the assigned numbers to the die facets, in which the number 5 indicates one possible outcome among six possibilities. Thus, again, $m *$ thinkers maintained abstract mathematical reasoning. Although such reasoning allowed them to acknowledge the sample space elements, they could not perceive these elements as signs of the die facets, which might or might not be symmetrical. Consequently, some $\mathbf{m}$ * thinkers further reported that for any random experiment with six possible outcomes, every event has one possibility among them to occur.

Admittedly, type m* reasoning is more relevant to Fischbein's (1987) determination of secondary intuitions emerged because of formal education to replace the primary preexisting intuitions. It forms a powerful tool that allows solving a problem without grasping all technical details (Borovcnik, 2016). That causes various obstacles for the application since 'the constituents of the modelling process are wider and also comprise - beyond mathematics knowledge of the context as well as criteria for assessing how well models match a situation' (Borovcnik, 2016, p. 1494).

\section{Characteristics of subjectively oriented thinkers [S $=\mathrm{s}, \mathrm{s} *$, and $\mathrm{s} * *$ reasoning]}

Interestingly, the category of subjectively oriented thinkers, noted by $\mathbf{S}$ and including $\mathbf{s}, \mathbf{s}^{*}$, and $\mathbf{s}^{* *}$, which matches nearly 60\% (41 cases from 68) of PSMTs' reasoning in the context of giving birth, did not emerge in the task of throwing a die. Such disappearance pulls us back to what was discussed earlier regarding the fruitfulness of the realistic contexts in displaying subjective probability. For illustration, the die regularity, numbers assigned to its sides, or knowledge of the person who manipulates the die were not reviewed by the respondents. Through such information, they can update their knowledge and further the probability when these additional information is recognised (Kvatinsky \& Even, 2002).

The common trait among $\mathbf{s}, \mathbf{s}^{*}$, and $\mathbf{s}^{* *}$ reasoning is that all are rooted in the subjective interpretation, wherein PSMTs utilised their personal information to determine the probability of giving birth to a girl. More precisely, to explain the factors that may alter their judgment. In this regard, $\mathbf{S}$ thinkers stressed the variability of the outcomes: the outcomes may vary depending on what they stated as contingencies (see Table 4). Therefore, their responses were expressed in the 'it depends' form, which is relevant to Bayesian reasoning that allows updating our estimation by processing new information (Batanero et al., 2016; Dollard, 2011; Sharma, 2016). Despite such commonality, s thinkers differed from both $\mathbf{s}^{*}$ and $\mathbf{s}^{* *}$ in understanding the concept of randomness which represents a crucial element to reason under uncertainty. In type s, the respondents stated that using an ultrasound scan might change the expected probability from $50 \%$ to $100 \%$ for sure. This means that they tend to change their estimation to certainty and deny randomness, which indicates the prediction bias (Briand, 
2005; Savard, 2008) since PSMTs' prediction had the meaning of exact prediction.

Alike this in omitting the notion of randomness that demands independence without correlation (Dessart, 1995; Green, 1993), one PSMT in the same category correlated the previous babies' gender with the newborn's gender. That is, past information provides a tool to predict the new outcome.

Yet, type $\mathbf{s}^{*}$ and $\mathbf{s * *}$ were not assigned to the same category. Although PSMTs in both categories maintained the notions of randomness and variability, the nature of the reasons was quite different. While type $\mathbf{s}^{* *}$ criteria and stated conditions remained cognitive and practical (see Table 4 ), in type $\mathbf{s}^{*}$, the respondents were inspired by the religious conception of Allah's will. Nevertheless, emphasising this conception did not restrict them from determining a probabilistic percentage. Also, s* thinkers adopted Allah's will not as a cause that influences the baby's gender, but rather to reveal some outof-control circumstances that may alter the predicted outcome.

Accordingly, as two PSMTs reported, the probability of giving birth to a girl equals 50\%; still, we cannot certainly anticipate a baby girl because it is a matter of Allah's will. In this matter, it is worthwhile to mention that animism attribution of phenomena to God was defined in multiple studies as a personalist interpretation (Amir \& Williams, 1999; Garfield \& Ben-Zvi, 2005; Kissane \& Kemp, 2010; Watson \& Moritz, 2003; Watson \& Kelly, 2004). However, in this study, this interpretation has been highlighted to be a certain level of probabilistic reasoning that needs more explanation.

In the viewpoint of Chassapis and Chatzivasileiou (2008), mathematics education and knowledge are culturally situated, so that they either implicitly or explicitly involve social and cultural values. Accordingly, beyond the mathematical aspect of each construct, there is another aspect associated with the practice of that construct in daily life. That explains why one mathematical concept can be valued in one context and de-valued in another. In this sense, the influence of sociocultural factors on the individuals' conceptions of probability was regarded (Larose, Bourque, \& Freiman, 2010; Sharma, 2016). In Chassapis and Chatzivasileiou's study, two groups from Jordan (Muslims) and Greece (Christians) were asked to attribute the unexpected event to one of chance, probability, fate, or God's will. The study revealed interesting findings, which support the claim regarding type $s^{*}$ reasoning: most Jordanian students assigned the unpredictability to God's will compared to the chance for the Greek students. Hence, Chassapis and Chatzivasileiou declared that because of the characterisation of the Jordanian context by the Muslim doctrine that affirms God's controllability of life, students' responses were accompanied by the phrase 'Insha'Allah' (if God wished it).

Such findings mirror the case of type $\mathrm{s}^{*}$ thinkers, where the respondents first determine the probability of giving birth to a girl; also, they added the term 'Insha'Allah' to reflect the limitedness of human beings in giving an exact prediction. Besides, $\mathbf{s}$ * responses were judged to be a certain level of probabilistic reasoning and not just a personalist interpretation (or a belief). While the PSMTs in the present study were asked to determine the probability and to reflect the circumstances that may alter their judgment, the participants of Chassapis and Chatzivasileiou's (2008) study were directed to attribute the cause of an unexpected event to one of chance, probability, fate, or God's will. This describes why their students' selection of 'God's will' was assessed as a causality. However, $\mathbf{s}$ * thinkers did not operate the concept of Allah's will as a cause of the baby's gender, but rather as one factor that may change the probability. Thus, they maintained their understanding of randomness without dependence or certainty and the variability by which the outcome may vary in terms of God's will. That is explicitly detailed by Chassapis and Chatzivasileiou as follows: 'Beliefs in God's will and probabilistic thinking may be compatible in some cases leaving space to the formation of chance and probability conceptions' (p. 204). This indicates how our religious beliefs influence conceptions of probability and probabilistic reasoning.

\section{Characteristics of outcome-oriented thinkers [O $=0,0 *$, and $0 * *$ reasoning]}

Type $\mathbf{0}, \mathbf{o}^{*}$, and $\mathbf{o}^{* *}$, denoted by $\mathbf{O}$, respondents are the outcome-oriented thinkers. They tried to handle the experimental probability to answer the inquiries. Although such utilisation involved several biases when PSMTs were asked to reason in the giving birth context, which caused the emergence of type $\mathbf{o}$ and $\mathbf{o}$ * categories, it was much better in the task of throwing a die. Because of that, the sub-category of type $\mathbf{o}^{* *}$ thinkers, which substantially deviates from $\mathbf{o}$ and o*, emerged only during the analysis of PSMTs' responses to the second task. In that sense, $\mathbf{o}^{* *}$ resembled $\mathbf{o}$ and $\mathbf{o}^{*}$ in manipulating the experimental probability; nonetheless, $\mathbf{o}^{* *}$ expressed a clear understanding of such a concept without biases. These discrepancies can be further detailed as follows.

First, type $\mathbf{o}$ and $\mathbf{o}$ * reasoning define PSMTs who focused on the favourable outcome (i.e., the exhibited outcome in the question) more than the probability. In the giving birth context, they understood the question as if it was: when would a woman give birth to a girl? (How to know, or under what circumstances?). Hence, they did not discuss the event of a baby girl as a possible event, but rather as a precise event that already occurred, and we are examining its causes (i.e., why has or has not it happened?). Accordingly, their responses assumed this woman is going to give birth to a girl if something appeared; similarly, if this thing did not happen, another gender is expected, in which case they attributed the phenomenon of giving birth to a girl to some causes. For instance, if the woman's belly shape is circular, she will give birth to a girl; likewise, if her belly shape is not circular, she will not give birth to a girl. Because of that, PSMTs' predictions were evaluated to be right or wrong, and their responses took 
the form of yes-no decisions concerning whether an outcome will occur in a particular case (i.e., the next expected gender will be a girl or not) (Batanero \& Sanchez, 2005; Konold, 1989; Savard, 2014).

In the second activity, $\mathbf{o}$ and $\mathbf{o}$ * respondents emphasised the outcome, number 5 itself, rather than its probability. Accordingly, the question was interpreted as how to get number 5: by what method, or how many trials are required to obtain number 5 ? Consequently, as shown in Table 5, eight cases explained their strategies to get a favourable outcome of 5. In detail, one PSMT reported that the experimenter could control the die, which is similar to the way many experts perform in Dominoes games. Another remarked that number 5 would certainly appear on the first try if the die has been designed to carry number 5 at all sides. Besides, two other PSMTs declared that 'it is impossible to get number 5 when throwing the die once'. One of them extended his answer by stating 'then, we have two possibilities; either (a) to increase the number of trials, or (b) to cheat the experiment and control the die by hand'. The other continued with 'the outcome cannot be determined in prior, rather after experimenting the die'. Although both responses tacitly indicated understanding the experimental probability as a long-term series of events, PSMTs' intention was not assigning the probability but rather getting the number 5. Also, four more PSMTs thought of the required number of trials at which number 5 is to appear. As they stated, it may arise at the first, second, or after six attempts.

Such exhibited reasoning of $\mathbf{o}$ and $\mathbf{o}$ * mirrors Konold's (1989) description of outcome-oriented thinkers. Instead of specifying probability, which reflects the distribution of occurrences in a series of events, PSMTs predict the result of $a$ single trial. Accordingly, as detailed, instead of determining the probability of (1) giving birth to a girl or (2) getting number 5, they explained the circumstances and strategies to obtain such favourable outcomes. Once again, the prediction bias emerged in $\mathbf{o}$ and $\mathbf{o}$ * responses. Yet, it was wielded by $\mathbf{s}$ thinkers differently. Although the term 'exact' referred to the probability that was judged by $\mathbf{s}$ thinkers precisely, without uncertainty (see Table 4), for o and o* thinkers, it indicates the outcome. Hence, while the attributed property 'exact' defines the probability in type s, it describes the outcome in types $\mathbf{o}$ and $\mathbf{o}^{*}$.

Expressly, in the task of throwing a die, some PSMTs realised the term 'once', meaning they cannot rely on the experimental probability unless the trails were increased. Still, they exposed their alternatives, including repeating the experiment several times to obtain number 5 (not to use the frequentist approach). Such an understanding of 'once' is operated based on the prediction bias: it oriented them towards classifying the sample space into (1) the favourable outcome and (2) all other events to satisfy their yes-no decision. For instance, if the woman's belly shape is rounded, she will give birth to a girl (i.e., the favourable outcome); if not, any other event will occur (e.g., boy, twins, miscarriage).
Still, and only in the context of giving birth, there is a clear difference between type $\mathbf{o}$ reasoning compared to $\mathbf{o}^{*}$ in terms of understanding of the notion of probability. In type o responses, PSMTs seem not to understand probability as quantification of our information regarding unknown phenomena. They discussed the favourable outcome of 'girl' not as a possible expected event but rather as if the random process had already happened, and its results became known. Accordingly, they stated that if the woman had a miscarriage during the delivery process, the probability would decrease from $50 \%$ to 0 (see Table 5). Such reasoning neglects that after the delivery process, the situation will not be probabilistic anymore at which point there is no purpose for the prediction itself. In contrast, although type $\mathbf{0}$ * thinkers understood the idea of prediction, they were less conscious of the distinction between causality and conditionality, wherein distinguishing both concepts has been recognised as a crucial determinant to reason probabilistically (Batanero et al., 2016). While dependence in probability characterises a bi-directional relation - if an event $B$ is the cause of another event $A$, then whenever $\mathrm{B}$ is present, $\mathrm{A}$ is present too (i.e., $\mathrm{P}(\mathrm{A} / \mathrm{B})=1$ ) - the two directions included in conditional probabilities have a distinct connotation from a causal viewpoint (Batanero et al., 2016; Díaz, Batanero, \& Contreras, 2010). For instance, although the conditional probability of having a baby girl to having a positive result on a sonar test is causal, the reversed direction from a positive diagnostic of sonar to having a baby girl is only indicative. Consequently, type o* thinkers share the causal conception since they assumed a causal relationship at which the conditioning event $\mathrm{B}$ is the cause and $\mathrm{A}$ is the consequence (Gras \& Totohasina, 1995; Savard, 2014).

Interestingly, on the other side of both $\mathbf{o}$ and $\mathbf{0}$, the category of type $\mathbf{o}^{* *}$ thinkers has emerged only in PSMTs' responses to the task of throwing a die. It denotes an adequate utilisation of the experimental probability, as noted at the beginning. Type $\mathbf{o}^{* *}$ thinkers focused on the probability, which, for them, remains a posterior judgment since it is necessary to gain data (frequencies) about the outcomes for estimating the relevant probability (Chernoff, 2008). Accordingly, they admitted the validity of the experimental interpretation to fulfil the situation of throwing a die if and only if the experiment has been repeated many times.

Furthermore, their responses indicated an awareness of the law of large numbers, in which they recognised the term 'once'. For example, two of them reported that:

the probability of getting number 5 equals $1 / 6$ through experimentations; yet, we cannot rely on one trial, rather the number of trials should be increased to make sure of the results and to get a more precise probability [i.e., theoretical probability].

Although such argumentation reflects an understanding of the variability wherein the calculated percentage varies depending upon the frequencies, both PSMTs still reported that the probability would be $1 / 6$. They either were keeping the theoretical probability in their mind to avoid ambiguity (Stohl, 2005) or they misused probability language, so instead of reporting that the probability may approach $1 / 6$ 
after a large number of identical trials, they just wrote: it will equal $1 / 6$.

Additionally, nine PSMTs in this category did not specify any percentage, but were concerned about the ratio of number 5 frequencies to the conducted trials. According to them, manipulating the experimental approach leads to different percentages that express the likelihood of getting 5 . They entirely understood the circumstances of the given situation; hence, the probability to obtain number 5, for them, depends on how many 5 s will appear in a large number of identical trials. They also further explicitly explained that as much as the number of experiments increased, the experimental probability approximates the theoretical percentage (i.e., the law of large numbers).

\section{Conclusion}

In conclusion, PSMTs' reasoning under uncertainty has been modelled into three major categories: Mathematically [M], Subjectively [S], and Outcome-oriented thinkers [O]. Yet, the exposed reasoning differs based not only on the individuals' knowledge but also on the context; that is exhibited clearly in Figure 2, which represents PSMTs' probabilistic reasoning in two different situations (i.e., giving birth and throwing a die).

As displayed in Figure 2, most PSMTs employed subjective reasoning when they were asked to speculate the problem of giving birth compared to the mathematical manner in the task of throwing a die. This can be interpreted in terms of two essential issues.

The first issue denotes PSMTs' familiarity with handling the traditional activities through manipulating the theoretical probability. Nonetheless, several biases were exposed when PSMTs employed this interpretation. For example, equiprobability and insensitivity to the prior probability of outcomes were exhibited in the context of giving birth when PSMTs judged the possibility of giving birth to a girl to be equal to a boy (or twins) and dropped the gender ratio at birth in Egypt. Similarly, they were reluctant to confirm the die regularity before operating Laplace theory in the task of throwing a die. Furthermore, the grounds under such biases stayed different between $\mathbf{m}$ and $\mathbf{m}^{*}$, the two subcategories of $\mathbf{M}$. On one side, $\mathbf{m}$ thinkers were influenced

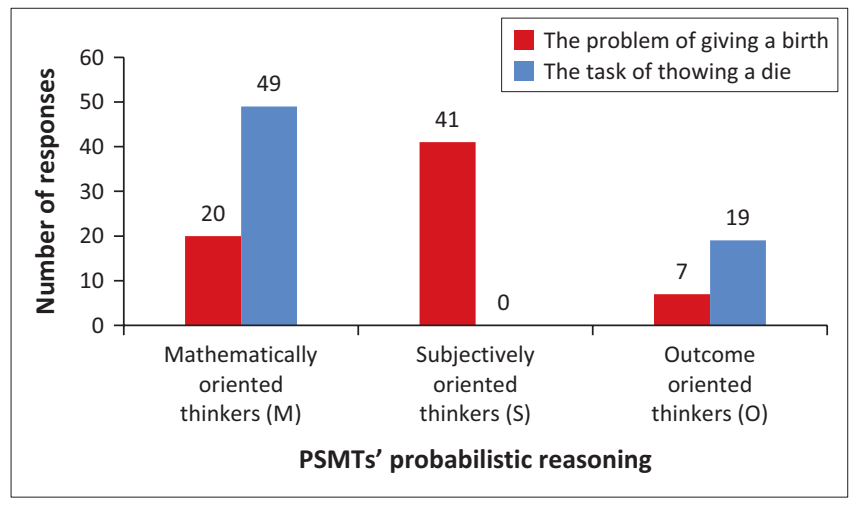

PSMT, preservice mathematics teachers.

FIGURE 2: PSMTs' probabilistic reasoning manners in two different contexts. by the representativeness heuristic: it oriented them to emphasise the random process and hindered verification of the required assumptions of theoretical probability. On the other side, equiprobable bias in type $\mathbf{m}^{*}$ was inherited in the overgeneralisation heuristic wherein the theoretical probability was overgeneralised to both situations (e.g., realistic and technical).

The second issue signifies the value of authentic contexts to display the subjective facet of the probability that implies a degree of belief in the truth of some premises. Although such interpretation did not appear in the context of throwing a die, it represented the majority of PSMTs' reasoning in the giving birth problem since around $60 \%$ of the participants were committed to type $\mathbf{S}$ thinkers and diverged among $\mathbf{s}, \mathbf{s}^{*}$, and $\mathbf{s} * *$ Yet, this reasoning involved some relevant biases. For instance, $\mathbf{s}$ thinkers shared the prediction bias that oriented them towards changing their estimation to certainty and denying randomness. Accordingly, in some cases, their prediction had the meaning of exact prediction; in other cases, their responses designated a correlation in which past information provides a tool to predict the new outcome. On the other side, type $\mathbf{s}^{*}$ and $\mathbf{s}^{* *}$ thinkers maintained the notions of randomness and variability. However, they attributed the variability of the random event to different circumstances.

Such circumstances varied between utilising realistic conditions (e.g., $\mathrm{X}$ and $\mathrm{Y}$ chromosomes, baby sonar) for $\mathbf{s}^{* *}$ thinkers, compared to sharing the religious conception of Allah's will for s*. In this regard, the emergence of Allah's will notified one interesting finding that was interpreted, in this study, as a certain level of probabilistic reasoning. This judgment was grounded in the sociocultural influence on the individuals' probability knowledge and reasoning (Chassapis \& Chatzivasileiou, 2008; Larose et al., 2010; Sharma, 2016), within Bishop's (1988) perspective on mathematics education as a cultural induction at which students' values remain an integral part of teaching and learning.

In addition to $\mathbf{M}$ and $\mathbf{S}$, another manner of reasoning emerged in PSMTs' responses to both situations and was termed type $\mathbf{O}$ thinkers. This reasoning involved manipulating the experimental probability with some biases in type $\mathbf{o}$ and $\mathbf{0}$ * compared to a clear understanding of this concept for $\mathbf{o}^{* *}$ thinkers.

On one hand, type o and $\mathbf{o}$ * responses typically mirror Konold's (1989) description of outcome-oriented thinkers. They focused on the favourable outcome more than its probability and understood the inquiry as if it was: when will this favourable outcome appear, and how to know or under what circumstances? Accordingly, their predictions were evaluated as right or wrong, and their responses took the form of yes-no decisions. Thus, instead of specifying probability, which reflects the distribution of occurrences in a series of events, PSMTs predict the result of a single trial. 
Also, although both $\mathbf{o}$ and $\mathbf{o}$ * thinkers decided to adapt the experimental probability as a posterior judgment, they failed to perform it appropriately because of the prediction bias. This emerged once again, yet in a different manner, with type $\mathbf{s}$ thinkers. The exact prediction referred to the probability for $\mathbf{s}$ thinkers and the outcome for both o and o* thinkers. Moreover, o thinkers did not fully grasp the probability that defines a quantification of our information regarding unknown phenomena. On the contrary, $\mathbf{o}^{*}$ thinkers were less conscious of the difference between causality and conditionality; they assumed a causal relationship between the conditioning event and the preferable outcome (i.e., causal conception).

On the other hand, besides both $\mathbf{o}$ and $\mathbf{o}^{*}, \mathbf{0}^{* *}$ thinkers reflected an adequate utilisation of the experimental probability. Accordingly, most $\mathbf{o}^{* *}$ thinkers did not specify any accurate percentage; instead, they were more concerned about the ratio of frequencies to the conducted trials. They further explicitly explained that as the number of experiments increased, the experimental probability approximates the theoretical percentage (i.e., the law of large numbers).

Indeed, these findings provided detailed insights into PSMTs' probabilistic reasoning that may work as learning trajectories, especially considering the inadequate preparation of PSMTs to teach probability, as noted in various studies. This acknowledges Batanero et al.'s (2004) recommendation regarding the necessity to consolidate a discussion on heuristics and biases within specific courses relevant to the didactics of probability. It further matches the current renaissance period of psychology research in mathematics education, which has been tacitly handled, in this study, through discussing PSMTs' knowledge of probability from a psychological perspective (i.e., probabilistic reasoning). Also, it incorporated a unified framework that models several probability conceptions in one schema (i.e., $\mathbf{M}, \mathbf{S}$, and $\mathbf{O}$ ), which may address the contested area regarding the nature of probability (i.e., mathematical and philosophical aspects). Further to this, from a national perspective, these results shed light on PSMTs' probability knowledge and reasoning under the umbrella of statistics education. Perhaps this responded to Innabi's (2014) recommendation regarding the need to stimulate the study of statistics in the Arab world, in which very little research has been conducted. Besides, it may activate PSMTs' awareness of their conceptions and biases that help them interpret similar biases in their prospective students' reasoning. Such a process is closely related to enhancing their Knowledge of Content and Students (KCS), which considers significant knowledge for the PSMTs to acquire.

Finally, there are some precautions about the results' interpretation; in other words, the study findings should not be generalised without considering certain conditions. One essential regard is the influence of the sociocultural factors in which the participants' values, an integral part of teaching and learning, need to be considered. Consequently, what can be acceptable in one context cannot be in another (e.g., Allah's will). Also, regarding the study questionnaire: since the individuals' reasoning differs depending not only on their knowledge but also on the context, the emerged categories of PSMTs' probabilistic reasoning might slightly vary because of the implemented problems. Accordingly, further research on PSMTs' probabilistic reasoning and related conceptions is demanded (different groups, different contexts, different questions) so that the study results can be verified.

\section{Acknowledgements}

I confirm that this work is original and not is currently under consideration for publication elsewhere. However, since this manuscript is a part of a $\mathrm{PhD}$ research, if it has been accepted for publication, I may contact you to get permission to release it (as included in the dissertation) in the Hiroshima University Institutional Repository.

\section{Competing interests}

The author has declared that no competing interest exist.

\section{Author's contributions}

I declare that I am the sole author of this research article.

\section{Ethical considerations}

This article followed all ethical standards for a research without direct contact with human or animal subjects.

\section{Funding information}

This research received no specific grant from any funding agency in the public, commercial, or not-for-profit sectors.

\section{Data availability}

As written in the acknowledgement section, the data provided in this research will be released in the Hiroshima University Institutional Repository.

\section{Disclaimer}

The views and opinions expressed in this article are those of the authors and do not necessarily reflect the official policy or position of any affiliated agency of the authors.

\section{References}

Ainley, J., \& Monteiro, C. (2008). Comparing curricular approaches for statistics in primary school in England and Brazil: A focus on graphing. In C. Batanero, G. Burrill, C. Reading, \& A. Rossman (Eds.), A joint ICMI/IASE study: Teaching statistics in school mathematics - Challenges for teaching and teacher education. Proceedings of the ICMI Study 18 and 2008 IASE Round Table Conference. Monterrey.

Aliaga, M., Cobb, G., Cuff, C., Garfield, J., Gould, R., Lock, R. ... Witmer, J. (2005). Guidelines for assessment and instruction in statistics education (GAISE) college report. Retrieved from http://www.amstat.org/education/gaise/

Amir, G.S., \& Williams, J.S. (1999). Cultural influences on children's probabilistic thinking. Journal of Mathematical Behavior, 18(1), 85-107. https://doi. org/10.1016/S0732-3123(99)00018-8

Elbehary, S.G.A. (2019). The necessity of revising primary school content of probability in Egypt to enhance students' probabilistic reasoning. In: S. Budgett (Ed.), Decision in Egypt to enhance students' probabilistic reasoning. In: S. Budgett (Ed.), Decision
making based on data. Proceedings of the Satellite conference of the International Association for Statistical Education (IASE), August 2019, Kuala Lumpur. 
Elbehary, S.G.A. (2020). Teacher education of statistics from theory to practice. Journal of Applied Research in Higher Education, 12(5), 857-869. https://doi. org/10.1108/JARHE-06-2019-0141

Azcárate, P., Cardeñoso, J.M., \& Serradó, S. (2006). Randomness in textbooks: The influence of deterministic thinking. In M. Bosch (Eds.), Proceedings of the Fourth Congress of European Research in Mathematics Education (pp. 559-568). Sant Feliu de Guixols.

Ball, D.L., Lubienski, S.T., \& Mewborn, D.S. (2001). Research on teaching mathematics: The unsolved problem of teachers' mathematical knowledge. In V. Richardson (Ed.), Handbook of research on teaching (pp. 433-456.). Washington, DC: American Educational Research Association.

Batanero, C., Burrill, G., \& Reading, C. (2011). Teaching statistics in school mathematics. Challenges for teaching and teacher education: A joint ICMI/IASE Study. Dordrecht: Springer.

Batanero, C., Chernoff, E., Engel, J., Lee, H., \& Sánchez, E. (2016). Research on teaching and learning probability. New York, NY: Springer. ICME-13. Topical Survey series.

Batanero, C., Contreras, J.M., Fernandes, J.A., \& Ojeda, M.M. (2010). Paradoxical games as a didactic tool to train teachers in probability In C Reading (Ed.), Dato and context in statistics education: Towards an evidence-based society. Proceedings of the Eighth International Conference on Teaching Statistics (ICOTS8). Ljubljana, Voorburg: International Statistical Institute.

Batanero, C., Godino J.D., \& Roa, R. (2004). Training teachers to teach probability. Journal of Statistics Education, 12(1), 1-15. https://doi.org/10.1080/10691898.20 Journal of Statist
04.11910715

Batanero, C., Green, D.R., \& Serrano, L.R. (1998). Randomness, its meanings and educational implications. International Journal of Mathematical Education in ScienceandTechnology,29(1),113-123.https://doi.org/10.1080/0020739980290111

Batanero, C., \& Sanchez, E. (2005). What is the nature of high school students' conceptions and misconceptions about probability? In G. Jones (Ed), Exploring probability in school: Challenges for teaching and learning (pp. 241-266). New York, NY: Springer.

Bishop, A.J. (1988). Mathematical enculturation: A cultural perspective on mathematics education. Dordrecht: Kluwer.

Borovcnik, M. (2016). Probabilistic thinking and probability literacy in the context of risk. Educação Matemática Pesquisa, 18(3), 1491-1516.

Borovcnik, M., \& Peard, R. (1996). Probability. In: A.J. Bishop, K. Clements, C. Keitel, J. Kilpatrick, \& C. Laborde (Eds.), International handbook of mathematics education. Kluwer international handbooks of education (pp. 239-287). Dordrecht: Springer.

Briand, J. (2005). Une expérience statistique et une première approche des lois du hasard au lycée par une confrontation avec une machine simple. Recherches en Didactique des sMathématiques, 25(2), 247-281.

Canada, D. (2006). Elementary pre-service teachers' conceptions of variation in a probability context. Statistics Education Research Journal, 5(1), 36-63.

Chassapis, D., \& Chatzivasileiou, E. (2008). Socio-cultural influences on children's conceptions of chance and probability. In J.F. Matos, P. Valero, \& K. Yasukawa (Eds.), Proceedings of the Fifth International Mathematics Education and Society Conference (pp. 197-206). Lisbon: Centro de Investigação em Educação, Universidade de Lisboa.

Chernoff, E.J. (2008). The state of probability measurement in mathematics education A first approximation. Philosophy of Mathematics Education Journal, 23, 1-23. Retrieved from http://socialsciences.exeter.ac.uk/education/research/centres/ stem/publications/pmej/pome23/index.htm

Chernoff, E.J. (2012). Recognizing revisitation of the representativeness heuristic: An analysis of answer key attributes. ZDM - The International Journal on Mathematics Education, 44(7), 941-952. https://doi.org/10.1007/s11858-012-0435-9

Chernoff, E.J., \& Russell, G.L. (2012). The fallacy of composition: Prospective mathematics teachers' use of logical fallacies. Canadian Journal of Science, Mathematics and Technology Education, 12(3), 259-271. https://doi.org/10.1080 /14926156.2012.704128

Chernoff, E.J., \& Russell, G.L. (2014). Preface to perspective I: Mathematics and philosophy. In E.J. Chernoff \& B. Sriraman (Eds.), Probabilistic thinking: Presenting plural perspectives (pp. 3-6). Berlin: Springer Science.

Chernoff, E.J., \& Sriraman, B. (2014). Introduction to probabilistic thinking: Presenting plural perspectives. In E.J. Chernoff \& B. Sriraman (Eds.), Probabilistic thinking: plural perspectives. In E.J. Chernoff \& B. Sriraman (Eds.), Probabilis
Presenting plural perspectives (pp. xv-xviii). Berlin: Springer Science.

Chernoff, E.J., \& Sriraman, B. (2015). The teaching and learning of probabilistic thinking: Heuristic, informal and fallacious reasoning. In R. Wegerif, L. Li, \& J. Kaufman (Eds.), The Routledge International Handbook of Research on Teaching Thinking (pp. 369-377). New York, NY: Routledge, Taylor \& Francis.

Chiesi, F., \& Primi, C. (2009). Assessing statistics attitudes among college students: Psychometric properties of the Italian version of the Survey of Attitudes toward Statistics (SATS). Learning and Individual Differences, 19(2), 309-313. https://doi. org/10.1016/j.lindif.2008.10.008

Creswell, J. (2009). Research design: Qualitative, quantitative, and mixed methods approaches (3rd ed.). Thousand Oaks, CA: Sage.

Darling-Hammond, L. (2000). Teacher quality and student achievement: A review of state policy evidence. Education Policy Analysis Archives, 8(1), 1-44. https://doi. org/10.14507/epaa.v8n1.2000

Darling-Hammond, L., \& Sykes, G. (2003). Wanted: A national teacher supply policy for education: The right way to meet the 'highly qualified teacher' challenge. Educational Policy Analysis Archives, 11(33), 1-55. https://doi.org/10.14507/ epaa.v11n33.2003

Dessart, D.J. (1995). Randomness: A connection to reality. In P.A. House \& A.F. Coxford (Eds.), Connecting mathematics across the curriculum (pp. 177-181). Reston, VA: National Council of Teachers of Mathematics, 1995 Yearbook.
Díaz, C., Batanero, C., \& Contreras, J.M. (2010). Teaching independence and conditional probability. Boletín de Estadística e Investigación Operativa, 26(2) 149-162.

Dollard, C. (2011). Preservice elementary teachers and the fundamentals of probability. Statistics Education Research Journal, 10(2), 27-47.

Elo, S., Kääriäinen, M., Kanste, O., Pölkki, T., Utriainen, K., \& Kyngäs, H. (2014). Qualitative content analysis: A focus on trustworthiness. SAGE Open, 4(1), 1-10. https://doi.org/10.1177/2158244014522633

Estrella, S., \& Olfos, R. (2010). Changing the understanding of probability in talented children. In C. Reading (Ed.), Data and context in statistics education: Towards an evidence-based society. Proceedings of the Eighth International Conference on Teaching Statistics (ICOTS 8), Ljubljana. Voorburg: International Statistical Institute.

Falk, R. (1986). Conditional probabilities: Insights and difficulties. In R. Davidson \& J. Swift (Eds.), Proceedings of the Second International Conference on Teaching Statistics (pp. 292-297). Victoria: International Statistical Institute.

Falk, R., \& Konold, C. (1992). The psychology of learning probability. In F.S. Gordon \& S.P. Gordon (Eds.), Statistics for the twenty-first century (pp. 151-164). Washington, DC: Mathematical Association of America.

Fennema, E., \& Franke, M. (1992). Teachers' knowledge and its impact. In D.A. Grouws (Ed.), Handbook of research on mathematics teaching and learning (pp. 147-164). New York, NY: Macmillan.

Fischbein, E. (1975). The intuitive source of probability thinking in children. Dordrecht: Reidel.

Fischbein, E. (1987). Intuition in science and mathematics: An educational approach Dordrecht: Reidel Pub.

Fischbein, E., \& Schnarch, D. (1997). The evolution with age of probabilistic: Intuitively based misconceptions. Journal of Research in Mathematics Education, 28(1), 95-106. https://doi.org/10.2307/749665

Franklin, C., \& Mewborn, D. (2006). The statistical education of PreK-12 teachers: A shared responsibility. In G. Burrill (Ed.), NCTM 2006 yearbook: Thinking and
reasoning with data and chance (pp. 335-344). Reston, VA: National Council of reasoning with data and
Teachers of Mathematics.

Garfield, J.B., \& Ben-Zvi, D. (2005). A framework for teaching and assessing reasoning about variability. Statistics Education Research Journal, 4(1), 92-99.

Gillard, E., Van Dooren, W., Schaeken, W., \& Verschaffel, L. (2009). Dual processes in the psychology of mathematics education and cognitive psychology. Human Development, 52(2), 95-108. https://doi.org/10.1159/000202728

Giordan, A. (1998). Apprendre! Paris: Belin.

Giordan, A., \& Pellaud, F. (2004). La place des conceptions dans la médiation de la chimie. L'actualité Chimique, 280(281), 49-52.

Gras, R., \& Totohasina, A. (1995). Chronologie et causalité, conceptions sources d'obstacles épistémologiques à la notion de probabilité conditionnelle. Recherche en Didactique des Mathématiques, 15(1), 49-55.

Green, D. (1993). Randomness - A key concept. International Journal of Mathematical Education in Science and Technology, 24(6), 897-905. https://doi.org/10.1080/ 0020739930240615

Hancock, D.R., \& Algozzine, B. (2006). Doing case study research: A practical guide for beginning research. New York, NY: Teachers College Press.

Heitele, D. (1975). An epistemological view on fundamental stochastic ideas. Educational Studies in Mathematics, 6, 187-205. https://doi.org/10.1007/ BF00302543

Ives, S. (2007). The relationship between preservice teachers' conceptions of randomness and their pedagogical content knowledge of probability. In D.K. Pugalee, A. Rogerson, \& A. Schinck (Eds.), Proceedings of the Ninth International Conference of Mathematics into the 21st Century Conference (pp. 318-322). Charlotte, NC: University of North Carolina at Charlotte.

Jones, G., Langrall, C., \& Mooney, E. (2007). Research in probability: Responding to classroom realities. In F. Lester (Ed.), Second handbook of research on mathematics teaching and learning (pp. 909-955). Greenwich, CT: Information Age Publishing and NCTM.

Kapadia, R., \& Borovcnik, M. (2010). Reviewing and promoting research in probability education electronically. In C. Reading (Ed.), Data and context in statistics education: Towards an evidence-based society. Proceedings of the Eighth education: Towards an evidence-based society. Proceedings of the Eighth
International Conference on Teaching Statistics (ICOTS8), Ljubljana. Voorburg: International Conference on Te
International Statistical Institute.

Kazak, S., \& Pratt, D. (2017). Pre-service mathematics teachers' use of probability models in making informal inferences about a chance game. Statistics Education Research Journal, 16(2), 287-304. https://doi.org/10.52041/serj.v16i2.193

Kissane, B., \& Kemp, M. (2010, December 17-21). Teaching and learning probability in the age of technology. Paper presented at the Fifteen Asian technology conference on mathematics, Kuala Lumpur.

Konold, C. (1989). Informal conceptions of probability. Cognition and Instruction, 6(1), 59-98. https://doi.org/10.1207/s1532690xci0601_3

Konold, C. (1991). Understanding student's beliefs about probability. In E.V. Glasersfeld (Ed.), Radical constructivism in mathematics education (pp. 139-156). Dordrecht: Kluwer Academic Publishers.

Konold, C., Pollatsek, A., Well, A., Lohmeier, J., \& Lipson, A. (1993). Inconsistencies in students' reasoning about probability. Journal for Research in Mathematics Education, 24(5), 392-414. https://doi.org/10.2307/749150

Kustos, P., \& Zelkowski, J. (2013). Grade-continuum trajectories of four known probabilistic misconceptions: What are students' perceptions of self-efficacy in completing probability tasks? The Journal of Mathematical Behavior, 32(3), 508-526. https://doi.org/10.1016/j.jmathb.2013.06.003 
Kvatinsky, T., \& Even, R. (2002). Framework for teacher knowledge and understanding of probability. In B. Phillips (Ed.), Proceedings of the Sixth International Conference
on the Teaching of Statistics (ICOTS6). Hawthorn: International Statistical Institute.

Larose, F., Bourque, J., \& Freiman, V. (2010). The effect of contextualising probability education on differentiating the concepts of luck, chance, and probabilities among middle and high school pupils in Quebec. In C. Reading (Ed), Data and context in statistics education: Towards an evidence based society. Proceedings of context in statistics education: Towards an evidence based society. Proceedings of the Eighth Internation
Statistics Institute.

Lecoutre, M. (1992). Cognitive models and problem spaces in purely random situations. Educational Studies in Mathematics, 23, 557-568. https://doi. org/10.1007/BF00540060

Lecoutre M.P., \& Fischbein E. (1998). Evolution avec l'âge de 'misconceptions' dans les intuitions probabilistes en France et en Israël [Evolution with age of probabilistic intuitions in France and Israel]. Recherches en Didactique des Mathématiques, 18(3), 311-332.

Linneberg, M.S., \& Korsgaard, S. (2019). Coding qualitative data: A synthesis guiding the novice. Qualitative Research Journal, 19(3), 259-270. https://doi.org/10.1108/ QRJ-12-2018-0012

Lopez, V., \& Whitehead, D. (2013). Sampling data and data collection in qualitative research. In Z. Schneider, D. Whitehead, G. LoBiondo-Wood, \& J. Habe (Eds.), Nursing and midwifery research: Methods and critical appraisal for evidencebased practice (pp. 124-140). Sydney: Mosby Elsevier.

Martignon, L. (2014). Fostering children's probabilistic reasoning and first elements of risk evaluation. In E.J. Chernoff \& B. Sriraman (Eds.), Probabilistic thinking: Presenting plural perspectives (pp. 149-160). Dordrecht: Springer.

Miles, M.B., Huberman A.M., \& Saldana, J. (2013). Qualitative data analysis: A methods sourcebook (4th ed.). Thousand Oaks, CA: Sage.

Moreno, A., \& Cardeñoso, J.M. (2014). Overview of prospective mathematics teachers' probabilistic thinking, In K. Makar, B. De Sousa, \& R. Gould (Eds.), Sustainability in statistics education. Proceedings of the Ninth International Sustainability in statistics education. Proceedings of the Ninth International
Conference on Teaching Statistics (ICOTS9), Flagstaff, AZ. Voorburg: International Conference on Teachir

Morris, A.K., Hiebert, J., \& Spitzer, S.M. (2009). Mathematical knowledge for teaching in planning and evaluating instruction: What can preservice teachers learn? Journal for Research in Mathematics Education, 5(40), 491-529. https://doi. Journal for Research in Mathematics
org/10.5951/jresematheduc.40.5.0491

Mosvold, R., \& Fauskanger, J. (2014). Teachers' beliefs about mathematical horizon content knowledge. International Journal for Mathematics Teaching and Learning, 9(3), 311-327.

Musch, J., \& Ehrenberg, K. (2002). Probability misjudgement, cognitive ability, and belief in the paranormal. British Journal of Psychology, 93(2), 169-177. https:// doi.org/10.1348/000712602162517

National Council of Teachers of Mathematics (NCTM). (1989). Curriculum and evaluation standards for school mathematics. Reston, VA: Author.

National Council of Teachers of Mathematics (NCTM). (2000). Principles and standards for school mathematics. Reston, VA: Author.

NationMaster. (2021). Egypt demographics profile. Retrieved from https://www. indexmundi.com/egypt/demographics_profile.html

Nisbett, R.E., Krantz, D.H., Jepson, C., \& Kunda, Z. (1983). The use of statistical heuristics in everyday inductive reasoning. Psychological Review, 90(4), 339-363. https://doi.org/10.1037/0033-295X.90.4.339

Pange, J., \& Talbot, M. (2003). Literature survey and children's perception on risk. ZDM - The International Journal on Mathematics Education, 35(4), 182-186. https:// doi.org/10.1007/BF02655740

Papaieronymou, I. (2010). Recommended knowledge of probability for secondary mathematics teachers. In V.D. Guerrier, S.S. Lavergne, \& F. Arzarello (Eds.), Proceedings at the 6th Congress of the European Society for Research in Mathematics Education (CERME6). Retrieved from http://ife.ens-lyon.fr/editions/ editions-electroniques/cerme6/

Pecky, R., \& Gould, R. (2005). Preparing secondary teachers to teach statistics: A distance education model. Invited paper at the International Statistical Institute 55 th Session, Sydney.
Piaget, J. (1975). L'équilibration des structures cognitives. Paris: Presses Universitaires de France.

Piaget, J., \& Inhelder, B. (1975). The origin of the idea of chance in children. New York, NY: Norton.

Pratt, D., \& Kazak, S. (2018). Research on uncertainty. In D. Ben-Zvi, K. Makar, \& J. Garfield (Eds.), International handbook of research in statistics education (pp. 193-227). Cham: Springer International Handbooks of Education.

Primi, C., Morsanyi, K., \& Chiesi, F. (2014). Measuring the basics of probabilistic reasoning: The IRT-based construction of the probabilistic reasoning questionnaire. In K. Makar, B. De Sousa, \& R. Gould (Eds.), Sustainability in statistics education. Proceedings of the Ninth International Conference on Teaching Statistics (ICOTS9), Flagstaff, AZ. Voorburg: International Statistical Institute.

Rivkin, S.G., Hanushek, E.A., \& Kain, J.F. (2005). Teachers, schools, and academic achievement. Econometrica, 73(2), 417-458. https://doi.org/10.1111/j.1468-0262. 2005.00584.x

Savard, A. (2008). From 'real life' to mathematics: A way for improving mathematical learning. Paper presented at the International Congress on Mathematical Education (ICME 11), Monterrey.

Savard, A. (2010). Simulating the risk without gambling: can student conceptions generate critical thinking about probability? In C. Reading (Ed.), Data and context generate critical thinking about probability? In C. Reading (Ed.), Data and context
in statistics education: Towards an evidence-based society. Proceedings of the in statistics education: Towards an evidence-based society. Proceedings of the
Eighth International Conference on Teaching Statistics (ICOTS8), Ljubljana. Voorburg: International Statistical Institute.

Savard, A. (2014). Developing probabilistic thinking: What about people's conceptions? In E.J. Chernoff \& B. Sriraman (Eds.), Probabilistic thinking: Presenting plural perspectives (pp. 283-298). Berlin: Springer.

Schacter, J., \& Thum, Y.M. (2004). Paying for high- and low-quality teaching. Economics of Education Review, 23(4), 411-430. https://doi.org/10.1016/j.econedurev.2003. 08.002

Sharma, S. (2016). Probability from a socio-cultural perspective. Statistics Education Research Journal, 15(2), 126-144. https://doi.org/10.52041/serj.v15i2.244

Shaughnessy, J.M. (1992). Research in probability and statistics: Reflections and directions. In D.A. Grouws (Ed.), Handbook of research on mathematics teaching and learning (pp. 465-494). New York, NY: Macmillan.

Stohl, H. (2005). Probability in teacher education and development. In G. Jones (Ed.), Exploring probability in school: Challenges for teaching and learning (pp. 345366). New York, NY: Springer.

Thomas, D. (2006). A general inductive approach for analysing qualitative evaluation data. American Journal of Evaluation, 27(2), 237-246. https://doi.org/10.1177/ 1098214005283748

Ticehurst, G.W., \& Veal, A.J. (2000). Business research methods: A managerial approach. Longman: Pearson Education Pty Limited.

Torres, G.E. (2014). Training prospective teachers for teaching probability at secondary school in Colombia. In K. Makar, B. De Sousa, \& R. Gould (Eds.), Sustainability in school in Colombia. In K. Makar, B. De Sousa, \& R. Gould (Eds.), Sustainability in statistics education. Proceedings of the Ninth International Conference on Teaching

Tversky, A., \& Kahneman, D. (1974). Judgment under uncertainty: Heuristics and biases. Science, 185(4157), 1124-1131. https://doi.org/10.1126/science.185.4157.1124

Watson, J., \& Moritz, J. (2003). Fairness of dice: A longitudinal study of students' beliefs and strategies for making judgments. Journal for Research in Mathematics Education, 34(4), 270-304. https://doi.org/10.2307/30034785

Watson, J.M., \& Kelly, B.A. (2004). Expectation versus variation: Students' decision making in a chance environment. Canadian Journal of Science, Mathematics and Technology Education, 4(3), 371-396. https://doi.org/10.1080/1492615040 9556620

Weyers, M.L., Strydom, H., \& Huisamen, A. (2008). Triangulation in social work research: The theory and examples of its practical application. Social Work/ Maatskaplike Werk, 44(2), 207-222. https://doi.org/10.15270/44-2-251

Yin, R.K. (2003). Case study research: Design and methods (2nd ed.). Thousand Oaks, CA: Sage. 


\section{Appendix 1}

\section{The probability contexts survey}

The following table summarizes seven various contexts at which the probability can be operated. Based on your understanding of theoretical, experimental, and conditional probability, could you determine the appropriateness of each situation to approach each probability interpretation? Please note that some contexts can be adapted to approach more than one concept (i.e., you may select multiple interpretations for each setting).

\begin{tabular}{|c|c|c|c|c|}
\hline \multirow[t]{2}{*}{ The situation } & \multirow[t]{2}{*}{ An example } & \multicolumn{3}{|c|}{ The probability interpretation } \\
\hline & & Theoretical & Experimental & Conditional \\
\hline To predict the weather circumstances & It is probable to rain tomorrow & & & \\
\hline $\begin{array}{l}\text { To predict the result of a handball match } \\
\text { for your school team }\end{array}$ & it is a weak possibility to win the handball competition & & & \\
\hline To predict the gender of a newborn baby & The probability of giving birth to a girl equals $50 \%$ & & & \\
\hline To express the status of a patient & The probability of living to 90 equals $40 \%$ & & & \\
\hline To express what we prefer & 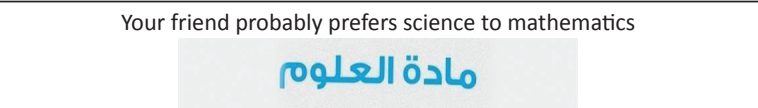 & & & \\
\hline To predict the quality of some products & The probability that the lamp produced by a factory is defective equals $3 \%$. & & & \\
\hline $\begin{array}{l}\text { To predict the winner for some chance } \\
\text { games }\end{array}$ & The probability of getting number 4 when throwing a die equals $3 \%$. & & & \\
\hline
\end{tabular}

